\section{Color-word interference in deaf and hearing children}

\author{
DORIS V. ALLEN*
}

Department of Audiology, Wayne State University, Detroit, Mich. 48202

Demonstrated differences between deaf and hearing Ss in learning and recall of verbal material may reflect differences in the initial apprehension of the stimuli or in the storage-retrieval process. The Stroop test was used to assess the apprehension of materials with a minimum contribution of memory. Results showed the deaf to be significantly faster on the interference task but slower at naming words alone than were hearing children of the same reading levels.

A number of studies suggest that Ss with severe hearing impairments employ strategies to retain and recall verbal material which are different from those used by hearing Ss (Allen, 1969, 1970; Blanton \& Nunnally, 1967; Blanton \& Odom, 1968; Conrad \& Rush, 1965; Odom \& Blanton, 1967). In general, the hearing Ss seem to use some aspects of the phonemic structure of words for memory, while the deaf use some other attributes as yet not identified.

Allen (1970) suggested that this difference may be at the root of the problems encountered in developing language in the deaf, that these differences may, in particular, account for their retarded reading skills. Since reading is basic to the entire educational experience and habilitation process, the importance of such differences becomes apparent.

All of the tasks used so far to demonstrate differences have involved verbal material and memory. Conrad \& Rush (1965) used letters of the alphabet in a short-term memory task, and Odom \& Blanton (1967) used memory for word phrases in one study and for trigrams differing in pronunciability ratings in another (Blanton \& Odom, 1968), as did Blanton \& Nunnally (1967), while Allen used rhyming words differing in spelling in a paired-associate paradigm $(1969,1970)$. Thus, differences in performance between deaf and hearing Ss may arise in the initial processing stage or in the retrieval stage. The present study attempted to identify the point at which the two groups diverge by assessing differences in initial processing.

The color-word interference task, first described by Stroop (1935), presents a method for evaluating apprehension of materials with a minimum contribution of memory. Three cards are used in this procedure,

*The author wishes to express her appreciation to Martin Robinette, a graduate student who has since obtained
$\mathrm{PhD}$, for his assistance with this study. one containing color patches, one containing the printed names of the colors, and a third on which the color names are printed in conflicting colors of ink (e.g., the word "red" is printed in yellow ink). The $S$ names the patches or words on the first two cards, and the time taken to complete each is recorded. These values provide an index of reading speed for colors alone and words alone. The third card is the test of interference; $S$ is required to name the color of the ink, not the word. This task requires much more time to complete. Although not all agree (e.g., Treisman \& Fearnley, 1969), the usual explanation for the increased time is that the word-reading habit is stronger than the color-naming habit and thus produces interference (Jensen \& Rohwer, 1966). One might say that whenever words are presented, the typical $S$ has difficulty not reading them and attending to other dimensions, i.e., he has a "compulsion to read."

Since reading speed is the criterion in this task, perception of the stimuli is the major variable being studied and aids in determining where the differences between the performance of hearing and hearing-impaired Ss arise. If reading levels of the hearing and deaf Ss are controlled, then the habit to read should be equally as strong in both groups and no difference should be obtained on the color-word task under the null
$* p<.05 ; \div p<.01$ hypothesis. However, if the differences already documented between deaf and hearing $S$ s reflect qualitatively different approaches to verbal tasks, as Allen $(1969,1970)$ has suggested, then a difference in performance on this task would be expected as well, with deaf performing better than hearing Ss.

\section{METHOD}

The specific materials used in this study consisted of three cards, $7 \times 5 \frac{1}{2}$ in., each with five rows and four columns of $1 \times 1 \mathrm{in}$. squares outlined in black, and a stopwatch. Card $C$, the color card, had a solid color in each square. Four colors were used: red, yellow, blue, and green. Each row had all four colors, but the sequence was different in each row. Card W, the word card, had one of the color names printed in black within each square. Again all color names appeared in each row, but the sequence differed. Card $\mathrm{CW}$, the color-word card, also had a color name printed in each square, but a conflicting color of ink was used to print the name. Each row contained all four colors, but the order differed in each row.

The Ss for this study were 7 deaf children and 17 hearing children. Deaf Ss were enrolled in a residential school for the deaf. They were required to have grade-equivalent reading levels of between 3.5 and 6.0 . This is an oral school, and all were considered to be good students. All had hearing losses averaging greater than $80 \mathrm{~dB}$; their ages ranged from 10 to 15 years, with a mean of 12.9 ; mean reading level was 4.3. The hearing Ss were in Grades 3-6 and performing at grade level; their ages ranged from 9 to 12 years, with a mean of 10.4 ; mean reading level was 5.0. Both sexes were represented in each group. The age difference between the groups is a natural result of matching for reading ability, since the deaf are slower at acquiring this skill.

The E, who was experienced in working with deaf children, sat beside the child and showed him Card C. The

Table 1

Time in Seconds for Hearing $(N=17)$ and Deaf $(N=7)$ Ss to Complete the Color-Word Interference Task

\begin{tabular}{lrrrrrr}
\hline & \multicolumn{2}{c}{ Hearing } & & \multicolumn{2}{c}{ Deaf } & \\
Scores & $\overline{\mathrm{X}}$ & $\mathrm{s}$ & & $\overline{\mathrm{X}}$ & $\mathrm{s}$ & $\mathrm{t}$ \\
\hline Basic & & & & & & \\
$\mathrm{C}$ & 12.45 & 3.28 & & 12.27 & 2.75 & .13 \\
$\mathrm{~W}$ & $\mathbf{8 . 6 5}$ & 1.70 & & 10.94 & 2.60 & $2.57^{*}$ \\
$\mathrm{CW}$ & 28.24 & 6.63 & & 22.21 & 2.30 & $3.30 \dagger$ \\
Derived & & & & & \\
C/W & 1.44 & .24 & & 1.14 & .17 & $3.00 \dagger$ \\
CW-C & 15.79 & 5.62 & .9 .94 & 2.54 & $2.62^{*}$ \\
$(\mathrm{C}-\mathrm{W}) / \mathrm{W}$ & .45 & .26 & .14 & .17 & $3.10 \dagger$ \\
\hline
\end{tabular}


Table 2

Intercorrelations Among Basic Scores for Adults and Children

Adults

Children

\begin{tabular}{|c|c|c|c|c|c|c|c|}
\hline Scores & Jensen $^{a}$ & \multicolumn{2}{|c|}{ Broverman ${ }^{2}$} & \multirow{2}{*}{$\frac{\text { Normalb }}{.57}$} & \multirow{2}{*}{$\frac{\begin{array}{r}\text { Retar- } \\
\text { date }\end{array}}{.48}$} & \multirow{2}{*}{$\frac{\begin{array}{c}\text { Hear- } \\
\text { ing }\end{array}}{.73 t}$} & \multirow{2}{*}{$\frac{\text { Deafc }}{.72^{*}}$} \\
\hline W vs C & .52 & .74 & .80 & & & & \\
\hline W vs CW & .43 & .57 & 63 & .50 & -.04 & .36 & $.72^{*}$ \\
\hline C vs CW & .66 & .76 & .81 & .58 & .27 & $.53^{*}$ & .50 \\
\hline
\end{tabular}

ajensen \& Rohwer, 1966; bas, 1969; cthis study

$*_{p}<.05, \pm p<.01$

$S$ was instructed to "say the colors you see as fast as you can." The E demonstrated by pointing to the colors in the top row from left to right while naming them aloud. The card was then rotated $180 \mathrm{deg}$, and $S$ was told to begin. Timing was begun as $S$ named the first color and ended when he named the last color. Card $W$ was presented next, and $S$ was told to read the color names as fast as he could; the time taken was recorded as before. Card CW was presented last, with instructions to name the color seen and not to read the word. The $E$ demonstrated by pointing to the square in the lower left corner, saying "you should say yellow, not red." The $S$ was then directed to the upper left corner of the card and told to begin. Timing was as for the other cards. All cards were held about 18 in. from $S$.

\section{RESULTS}

Table 1 summarizes the performance of the two groups of children on the three cards of the task. As shown there, the groups did not differ in the amount of time taken to read the color card, but the deaf were both significantly slower in reading Card $W$ and faster in completing the $\mathrm{CW}$ card. Adjusting the $\mathrm{CW}$ scores for differences in $W$, using analysis of covariance, still yielded a significant difference between groups, $F(1,21)=8.97, p<.01$. Thus, the deaf Ss were slower at reading the color names, and they named the color of the $\mathrm{CW}$ card faster than did the hearing Ss.

While these results satisfied the original purpose of the study, additional aspects of the data were examined in order to gain further insight into the differences in performance between the two groups. A number of different scoring formulas for the Stroop test have been used by different authors to index different psychological variables (Jensen \& Rohwer, 1966). Those that seem most relevant to the groups used here are $\mathrm{C} / \mathrm{W},(\mathrm{CW}-\mathrm{C})$, and $(\mathrm{C}-\mathrm{W}) / \mathrm{W}$, termed indices of verbainess, interference proneness, and verbal specialization, respectively. These data are also summarized in
Table 1 and show that hearing Ss scored significantly higher than the deaf $S s$ on all three measures.

The correlations between the times taken to complete each of the cards were also examined. Table 2 presents the intercorrelations among the three measures for the two groups, along with typical values for these same measures as reported by others. The correlations obtained for the hearing children in this study are compatible with these other values in that the $W$ vs $\mathrm{CW}$ relationship is the weakest. More interesting is the pattern of intercorrelations obtained for the deaf. For them, the relationship between W and $\mathrm{CW}$ was one of the strongest, the remaining intercorrelations being similar to those for hearing Ss.

\section{DISCUSSION}

The finding that the deaf exhibited less interference on the conflicting $\mathrm{CW}$ card than did the hearing children lends further support to the assumption that the differences observed between hearing and hearing-impaired groups in a number of studies is related to differences in how they initially process the material or stimulus situation. The deaf do not show a "compulsion to read" to the same degree as do hearing children when confronted with verbal material. The fact that the deaf were slower on $C$ ard $W$ was surprising and may indicate that the grade-equivalent reading levels were not an adequate basis for comparing groups. However, this slower performance may be yet another indication of fundamental differences between the hearing and the deaf. The score for $W$ has been termed the only clear-cut measure of a speed factor (Jensen \& Rohwer, 1966); the difference obtained may mean that the deaf are slower in "personal tempo" and may bear no relationship to reading ability.

Certainly the difference between groups in reading speed for words alone does not weaken the significance of the $\mathrm{CW}$ score difference, as shown by the analysis of covariance. The correlations reported between $W$ and $\mathrm{CW}$ are always positive, indicating that faster readers for words alone are also fast at color. The fact that the deaf show an exceptionally strong relationship between $W$ and $C W$ adds further weight to the assumption that the deaf are not just "normal" people who cannot hear. The derived scores emphasize the difference between the performance of the hearing and the deaf. As expected, the hearing $S s$ scored higher on verbalness and verbal specialization, while the deaf were less prone to interference using these indices.

The results of this study, then, suggest even more strongly that the hearing-impaired use strategies for apprehending and processing verbal material that are qualitatively different from those used by hearing Ss. The deaf seem able to view verbal material without attending to its "verbalness," i.e., they can view words as they do objects and thus can easily attend to other characteristics of the stimuli. In contrast, hearing $S s$ have great difficulty in responding to anything other than the word itself. The techniques used for education and habilitation of the hearing-impaired should be evaluated in terms of this difference; perhaps, with more suitable methods, the linguistic problems of the deaf can be more easily resolved.

\section{REFERENCES}

ALLEN, D. V. Modality aspects of mediation in children with normal and with impaired hearing ability. Final report, Project No, 7.0837, U.S. Office of Education, Department of Health, Education, and Welfare, 1969 ,

ALLEN, D. $V$. Acoustic interference in paired-associate learning as a function of hearing ability. Psychonomic Science. $1970,18,231-233$

BLANTON, R. L., \& NUNNALLY, J.C. Retention of trigrams by deaf and hearing subjects as a function of pronunciability. Joumal of Verbal Learning \& Verbal Behavior, $1967,6,428-431$.

BLANTON, R. L., \& ODOM, P. B. Some possible interference and facilitation effects of pronunciability. Journal of Verbal Learning \& Verbal Behavior, $1968,7,844-846$.

CONRAD, R.. \& RUSH, M, L, On the nature of short-term memory encoding by the deaf. Journal of Speech \& Hearing Disorders, $1965,30,336-343$.

DAS, J. P. Development of verbal abilities in retarded and normal children as measured by Stroop test. British Journal of Social \& Clinical Psychology, 1969, 8, 59-66.

JENSEN, A. R.. \& ROHWER, W. D., JR The Stroop Color-Word Test: A review. Acta Psychologica, 1966, 25, 36-93.

ODOM, P. B., \& BLANTON, R. L. Phrase-learning in deaf and hearing subjects. Joumal of Speech \& Hearing Research, 1967, 10,600-605.

STROOP, J. R. Studies of interference in serial verbal reactions. Joumal of Experimental Psychology, 1935, 18, 643-661.

TREISMAN, A., \& FEARNLEY, S. The Stroop test: Selective attention to colours and words. Nature, $1969,222,437-439$ 